\title{
DISCUSSÃO ÉTICA SOBRE A PRIVATIZAÇÃO DAS PRISÕES NOS ESTADOS UNIDOS DA AMÉRICA
}

\section{ETHICS DISCUSSION ON THE PRIVATIZATON OF PRISONS IN THE UNITED STATES OF AMERICA}

\author{
Augustus Bonner Cochran III ${ }^{1}$ \\ Fernando Gustavo Knoerr² \\ Marcelo de Souza Sampaio ${ }^{3}$
}

\section{RESUMO}

O objetivo do presente estudo é pesquisar sobre as questões éticas relativas à privatização de prisões nos Estados Unidos da America, que ocorreu com mais intensidade a partir de 1980, época em que houve uma superlotação dos presídios em função da alta criminalidade e iniciou-se o questionamento da eficiência do Estado em gerar as prisões do ponto de vista financeiro. A metodologia utilizada para a concretização dos objetivos do presente artigo foi a pesquisa bibliográfica, utilizando-se o método dedutivo, mediante a leitura de livros, artigos científicos e sítios da internet que abordam os temas de privatização prisional e ética. Concluiu-se da pesquisa que as questões éticas discutidas na mídia e na sociedade estão levando os governos estaduais a rever seu posicionamento sobre o tema, com uma tendência ao abandono das prisões geridas por empresas privadas, por haver muitas dúvidas sobre a real eficácia dessa privatização e também pelo repúdio da população baseada nos motivos éticos, valores fundamentais da pessoa humana e a dignidade da população encarcerada.

\footnotetext{
1 Doctor Public Policy pela University of North Carolina - Multi-Campus University (1972).

2 Doutor em Direito do Estado pela Universidade Federal do Paraná (2002). Mestre em Direito do Estado pela Universidade Federal do Paraná (1998). Bacharel em Direito pela Universidade Federal do Paraná (1993). ExProcurador Federal. Professor de Direito Administrativo da Escola da Magistratura do Paraná e da Fundação Escola do Ministério Público do Paraná / FEMPAR. É Professor Permanente do Programa de Mestrado em Direito Empresarial e Cidadania do UNICURITIBA. Realizou estágio Pós- Doutoral na Universidade de Coimbra, Portugal (2015-2016).

${ }^{3}$ Doutorando e Mestre em Direito Empresarial e Cidadania pelo Centro Universitário Curitiba - UNICURITIBA. Bacharel em Direito pela Universidade Tuiuti do Paraná - UTP. Especialista em Direito Processual pela Universidade Tuiuti do Paraná - UTP. Atualmente é Coordenador e Professor do curso de BACHARELADO em Direito e da Área de Humanas e Sociais Aplicadas do Centro Universitário de Maringá - UNICESUMAR. Campus Curitiba. E-mail: marcelo@sampaioadv.com.br.
} 
PALAVRAS-CHAVE: ética; prisão; privatização; dignidade; reincidência.

\begin{abstract}
The objective of the present study is to investigate the ethical issues related to the privatization of prisons in the United States of America, which occurred more intensely as of 1980, when there was an overcrowding of prisons due to high crime and the questioning of efficiency of the State in managing prisons from a financial point of view. The methodology used to achieve the objectives of this article is the bibliographic research, using the deductive method, by reading books, scientific articles and websites that address the themes of prison and ethical privatization. It is concluded from the research that the ethical issues discussed in the media and society are leading state governments to review their position on the issue, with a tendency to abandon prisons run by private companies, as there are many doubts about the real effectiveness of this privatization and also due to the repudiation of the population based on ethical motives, fundamental values of the human being and the dignity of the incarcerated population.
\end{abstract}

KEYWORDS: ethics; prison; privatization; dignity; recidivism. 


\section{INTRODUÇÃO}

Nos últimos trinta anos o governo dos Estados Unidos da América, do Reino Unido, da Austrália, do Canadá, da Nova Zelândia, das Antilhas Holandesas e da África do Sul renunciaram à sua obrigação de controlar, disciplinar e punir sua população que praticou infrações criminais em favor de empresas privadas com fins lucrativos. Deu-se a esta tendência o termo de "privatização" que, na verdade, cobre um rol de atividades.

Esta nova política foi estabelecida em função da superlotação das prisões e também da crença de que o Estado era financeiramente ineficiente para administrar os custos das prisões. Por esses motivos, o Estado foi forçado a procurar alternativas para encarcerar os infratores em centros correcionais. Uma das alternativas encontradas foi a privatização correcional, que gera há décadas muitos debates sobre as questões éticas envolvidas nesta estratégia privatizante de um Estado voltado integramente ao neoliberalismo.

Muito do discurso sobre este tema está centrado em questões éticas e empíricas, incluindo o seguinte: O Estado pode renunciar à sua obrigação de punir? Pode delegar essa função a empresas privadas que visam o lucro, em um tema que diz respeito unicamente ao Estado? Será que realmente há redução dos custos na gestão privada de prisões? Como a empresa privada resolve o conflito de interesse entre a busca do lucro e a prestação de um serviço que é estatal e visa à reintegração dos infratores à sociedade? O bem-estar e a dignidade da população encarcerada não estão em risco nas mãos de uma empresa que visa lucro? Um infrator que permaneceu em uma prisão privada tem menos probabilidade de reincidir? As prisões privadas fazem uma gestão mais eficiente do que gestão pública? No tempo certo, talvez, as respostas e outros questionamentos serão esclarecidos.

No capítulo segundo abordar-se-á aspectos históricos que levaram à privatização de prisões nos Estados Unidos da América desde o século XIX, com maior ênfase a partir de 1980, com o aumento da criminalidade e da superlotação das prisões.

Discute-se no capítulo terceiro o comportamento ético tanto dos agentes do governo privatizadores quanto dos gestores das prisões privadas em detrimento da população carcerária, que passa a ser considerada uma mercadoria, na medida em que as prisões privadas têm de manter-se com o máximo de camas utilizadas para obter o seu desejado lucro sobre o negócio contratado com o governo. 
O quarto capítulo trata da discussão sobre a continuidade ou não da política de privatização de prisões em função das questões éticas e do repúdio da população sobre o tema; e por fim as considerações finais sobre o tema.

A metodologia utilizada para a concretização dos objetivos do presente artigo foi a pesquisa bibliográfica, utilizando-se o método dedutivo, mediante a leitura de livros, artigos científicos e sítios da internet que abordam os temas de privatização prisional e ética.

\section{A PRIVATIZAÇÃO DE PRISÕES NOS ESTADOS UNIDOS DA AMÉRICA}

A privatização ocorre quando órgãos públicos, como departamentos correcionais, contratam serviços, programas ou operações de organizações ou empresas externas com fins lucrativos para operar uma instalação prisional. Esses contratos transferem do setor público para o setor privado a responsabilidade para atuar em certos aspectos das correções. ${ }^{2}$

As empresas privadas geralmente cobram do governo um valor diário por preso para cobrir o investimento, a operação, os custos e o lucro. ${ }^{3}$ Normalmente esse valor inclui a maioria dos serviços necessários para operar um sistema prisional, incluindo guardas, colaboradores, alimentos, programa de custos, atendimento médico parcial e outros serviços. Atualmente, muitas das grandes empresas que operam prisões são entidades privadas de capital aberto. ${ }^{4}$

Embora a privatização possa parecer uma tendência relativamente moderna no sistema penal estadunidense, há uma longa história de envolvimento do setor privado no gerenciamento de prisões. Em vários momentos do século XIX, os governos estaduais nos Estados Unidos da América contrataram a operação de suas instalações correcionais com empreendedores privados, que então utilizariam trabalho de detentos em benefício.

\footnotetext{
2 STARR, Paul. (1988). The meaning of privatization. Yale Law and Policy Review, 6, 6-41.1981. Disponível em: < https://www.princeton.edu/ starr/articles/articles80-89/Starr-MeaningPrivatization-88.htm>. Acesso em: 2 jan. 2020.

${ }^{3}$ SILVA, Nicole Mitchell Ribeiro. O Trabalho nas Prisões dos EUA: "Não É um Sistema de Justiça, É um Negócio" Disponível em: <http://www.mprj.mp.br/documents/20184/1183784/Nicole_Mitchell_Ribeiro_da_Silva.pdf>.

${ }^{4}$ LUNDHAL, Brad. W. Prison Privatization A Meta-analysis of Cost and Quality of Confinement Indicators.

Research on Social Work Practice. v.19 nr. Sage Publications: 2009. Disponível em: <https://www.epsu.org/sites/default/files/article/files/luhndahl-prisons-.pdf>. Acesso em: 2 jan. 2020.
} 
O estado de Kentucky foi o primeiro a contratar um empreiteiro privado no ano de 1825 , para gerenciar todo o seu sistema correcional. Posteriormente, no final da Guerra Civil, a maioria dos estados do sul havia seguido o exemplo do estado de Kentucky. ${ }^{5}$ Nas últimas décadas do século XIX, no entanto, as prisões privadas foram atacadas por uma ampla coalizão de trabalhadores que argumentavam a existência da prática de concorrência desleal contra o trabalho de detentos e também por reformadores que protestavam contra as más condições de confinamento em instalações privadas. No início do século $\mathrm{XX}$, o governo assumiu a responsabilidade pelo encarceramento e pela maioria das outras funções de Justiça Criminal e, por conseguinte, os empresários privados não administravam mais instituições correcionais para adultos. ${ }^{6}$

Após o fim das prisões de operação privada no final do século XIX, os governos federais e estaduais nos Estados Unidos continuaram a empregar empresas privadas para fornecer uma variedade de serviços específicos para instalações correcionais, como produção de alimentos, programas educacionais, treinamento vocacional e aconselhamento. Desde a década de 1960, o Federal Bureau of Prisons contratava empresas privadas para administrar centros comunitários de tratamento e casas de recuperação para onde os prisioneiros federais foram transferidos antes da liberdade condicional. ${ }^{7}$

A partir de 1979, o Serviço de Imigração e Naturalização havia contratado empresas privadas para administrar centros de detenção de imigrantes ilegais suspeitos. ${ }^{8}$ As empresas começaram a operar prisões privadas em âmbito local e estadual a partir de 1988. Naquela época, vinte instalações federais de detenção operadas em âmbito estadual e municipal estavam em operação em nove estados. Nos anos 1980, o tamanho da instalação média de prisões privadas aumentou, considerando-se que no período experimental inicial as prisões privadas contavam com oitenta camas e posteriormente aumentaram para 500 e 600 camas. ${ }^{9}$ O retorno da gestão de instalações correcionais por empresas privadas, no entanto, despertou uma reação imediata.

\footnotetext{
${ }^{5}$ LONG, Charles H. Private prisons: cons and pros. New York: Oxford University Press: 1990.

${ }^{6}$ POSEN, David E. Managing a Correctional Marketplace: Prison Privatization in the United States of America and United Kingdom.2003. Disponível em:〈http://www.antoniocasella.eu/nume/Pozen_prison_privatization_2003.pdf $>$. Acesso em: 31 dez. 2019.

${ }^{7}$ HACKETT, Judith et. Al. Issues in Contracting for the Private Operations of Prison and Jails. Oct. 1987. Disponível em: <https://books.google.com.br>. Acesso em: 31 dez. 2019.

8 OSTERMANN, Fábio Maia. A PRIVATIZAÇÃo DE PRESídios COMO ALTERNATIVA AO CAOS

PRISIONAL. Disponível em: < https://www.ufrgs.br/ressevera/wp-content/uploads/2010/08/v02-n01-artigo02privatizacao.pdf $>$. Acesso em: 3 jan.2020.

${ }^{9}$ LUNDHAL , 2009.
} 
Como dito acima, embora a privatização tenha sido uma característica das correções estadunidenses desde o início do século XIX, os Estados Unidos da América começaram a utilizar prisões privadas nos anos 1980, época em que a utilização de sentenças e sua efetiva execução era a resposta a uma onda de criminalidade, em meio à guerra às drogas, acarretando a explosão da população carcerária. ${ }^{10}$

A privatização surgiu como resposta a ambas as demandas. Como os Estados Unidos da América empreenderam um dos maiores programas de construção de prisões em sua história durante os anos 80, o esforço do recrutamento do setor privado ofereceu uma chance de expandir a capacidade mais rápida e possivelmente mais barata. Empreiteiros privados poderiam acrescentar ainda mais urgência e flexibilidade, pois a maioria dos governos estaduais financia a construção de prisões por meio de emissão de títulos, que geralmente estão sujeitos à aprovação dos eleitores por referendo. ${ }^{11}$

Durante o final da década de 1970 e o início da década de 1980, os cidadãos frequentemente rejeitaram as propostas de prisão privada, mesmo exigindo simultaneamente a prisão de mais criminosos. Portanto, as autoridades estaduais começaram a ignorar os referendos dos eleitores por questões de vínculo, recorrendo a acordos de recompra de contratos com empresas privadas para o projeto, construção, administração e financiamento das prisões, que permitiram os pagamentos de aluguel por meio do orçamento operacional do estado, e não pelas contas de capital. ${ }^{12}$

Além de um financiamento mais fácil e potencialmente mais barato para a construção de novas prisões, muitos funcionários correcionais acreditavam que a privatização geraria economia de custos por meio da redução de despesas operacionais. Os primeiros relatórios patrocinados pelo governo sobre privatização de prisões nos Estados Unidos apresentaram o argumento padrão de que os motivos de lucro das empresas privadas permitiriam que eles realizassem tarefas de prisão de maneira mais econômica. ${ }^{13}$

As agências correcionais esperavam que esses ganhos de eficiência com a contratação economizassem dinheiro todos os anos. Alguns estados explicitaram essa expectativa, como

\footnotetext{
${ }^{10}$ STILLMAN, Sarah. Get Out of Jail, Inc. Does the alternatives-to-incarceration industry profit from injustice? June 23, 2014 Issue. Disponível em: <https://www.newyorker.com/magazine/2014/06/23/get-out-ofjail-inc>. Acesso em: 1 jan. 2020

${ }^{11}$ HARDING, Richard, Private Prisons, in Crime and Justice: Review of Research. Michael H. Tonry ed.: 2001, p. $265,268-269$.

${ }^{12}$ HARDING. Ibid.

${ }^{13}$ HARDING, 2001.
} 
no requisito estatutário da Flórida, de que sua Comissão Correcional de Privatização "não possa celebrar um contrato. . a menos que determine que o contrato ou a série de contratos no total para a instalação resultará em uma economia de custos para o estado de pelo menos sete por cento sobre a provisão pública de uma instalação semelhante". ${ }^{14}$

Por consequência das condições deterioradas nas prisões públicas, a privatização também oferecia a possibilidade de reforma penitenciária. Havia muitas variantes desse argumento, mas geralmente os defensores da privatização argumentavam que a experiência gerencial e mecanismos aprimorados de prestação de contas de empreiteiros particulares permitiram-lhes prestar serviços prisionais de maior qualidade e menor custo, embora o Serviço Penitenciário não tenha enfrentado ordens judiciais para melhorar as condições da prisão. ${ }^{15}$

A tendência de privatizar prisões começou mais intensamente em 1984, quando Hamilton County, Tennessee e Bay County, localizados no estado da Flórida, celebraram contratos com o setor privado. ${ }^{16}$

A indústria de prisões privadas começou a aproximar-se dos governos e sugerir que se poderia encarcerar pessoas a um custo menor e ajudar a combater a superlotação; mas, ao mesmo tempo, também estavam prometendo um retorno lucrativo a seus acionistas. ${ }^{17}$

O Congresso realizou audiências sobre a privatização correcional em 1986 e a maioria das associações profissionais de justiça criminal tomaram uma posição sobre o assunto. Apesar dos protestos de muitos, a privatização nos Estados Unidos da América continuou em ritmo acelerado, com o aumento entre 1991 e 1998 de $856 \%$ da capacidade de instalações prisionais privadas seguras para adultos. ${ }^{18}$

\footnotetext{
${ }^{14}$ Texto original em inglês: "may not enter into a contract . . unless [it] determines that the contract or series of contracts in total for the facility will result in a cost savings to

the state of at least seven percent over the public provision of a similar facility." Fla. Stat. Ann. §957.07 (West 1993)

15 POZEN, 2003.

${ }^{16}$ ANDERSON, George. Prisons for Profit: Some ethical and practical problems. Nov., 2018.

Disponível em: <https://www.americamagazine.org/issue/389/article/prisons-profit>. Acesso em 31 dez. 2019.

${ }^{17}$ LINDSEY, Andrea M. The Privatization Debate: A Conceptual Framework for Improving (Public and Private) Corrections. 2016.

Disponível em: <https://www.researchgate.net/publication/305418634_The_Privatization_Debate_A_Conceptual_Framework_f or_Improving_Public_and_Private_Corrections/link/5a1d8d540f7e9b2a531768ce/download>. Acesso em: 2 jan. 2020

18 ARMSTRONG, Gaylene Styve. Private vs. Public Operation of Juvenile Correctional Facilities. New York: LFB Scholarly Publishing LLC, 2001.
} 
O tipo e a classificação das instalações de operação privada mudaram de padrão de segurança predominantemente baixo em muitas instalações, para níveis de segurança médio e máximo para várias instalações que abrigavam presos em todos os níveis de segurança. ${ }^{19}$ Em 1990, havia empresas privadas correcionais com 15.000 camas; em 1996 esse número aumentou $435 \% .^{20}$ No final de 1999, 14 empresas operavam mais de 150 penitenciárias para adultos, esclarecendo-se que 17 delas aferiam receitas anuais combinadas superiores a um bilhão de dólares. $^{21}$

Até o ano 2000, as prisões de operação privada mantinham mais de 101.000 presos federais, estaduais e municipais. Na época, esse número representava $11 \%$ de todos os presos federais, $6 \%$ de todos os presos estaduais e $2 \%$ dos presos municipais. A maioria das operações penitenciárias privadas (63\%) estava concentrada nos estados do Sul. O estado do Texas tinha a maior prisão privada, com capacidade para 30.000 camas. ${ }^{22}$ Em 2004, 31 estados usavam 158 estabelecimentos prisionais privados projetados para abrigar 122.871 internos. $^{23}$

O movimento de privatização das prisões dos Estados Unidos foi motivado por um conjunto comum de fatores, dentre eles a percepção de uma crise nas correções e a preferência ideológica do governo por incentivar a livre empresa e a diminuir o papel do trabalho sindicalizado. ${ }^{24}$ Várias razões adicionais foram citadas para esse aparente aumento, incluindo questões dos sistemas correcionais locais, estaduais e federais quanto: (1) a preocupações com o rápido crescimento das populações encarceradas e seus custos associados; (2) à superlotação em prisões que poderiam afetar a segurança e o bem-estar da população correcional e do público; (3) ao custo de gerenciar efetivamente grandes populações correcionais; (4) à capacidade das penitenciárias em alcançar objetivos críticos e fazê-lo de maneira econômica, incluindo a capacidade de gerenciar rapidamente o processo burocrático, e (5) à necessidade de

\footnotetext{
${ }^{19}$ CALVERT-HANSON, L. S. The privatization of corrections movement:

A decade of change. Journal of Contemporary Criminal Justice, 1991, 7, 1-20. Disponível em: <https://journals.sagepub.com/doi/pdf/10.1177/104398629100700103>. Acesso em: 3 jan. 2020.

${ }^{20}$ BLAKELY, Curtis R. Blakely; BUMPHUS, Vic W. Bumphus,

Private and Public Sector Prisons: A Comparison of Select Characteristics, jun. 2004,

Disponível em: <https://www.uscourts.gov/federal-probation-journal/2004/06/private-and-public-sector-prisonscomparison-select>. Acesso em: 2 jan. 2020.

${ }^{21}$ POZEN, 2003.

${ }^{22}$ CHANG, Tracy F.H.;THOMPKINS, Douglas E. Corporations Go to Prisons: The Expansion of Corporate Power in the Correctional Industry. Disponível em: <https://citeseerx.ist.psu.edu/viewdoc/download;jsessionid=6636C45A3014B5ED8EC0625E2B8F4126?doi=10. 1.1.462.6544\&rep=rep1\&type=pdf $>$. Acesso em: 2 jan. 2020.

${ }^{23}$ Blakely, 2004.

${ }^{24}$ POZEN, 2003.
} 
maior flexibilidade na adaptação às mudanças, como o aumento dramático de casos no sistema correcional que começaram na década de $1980 .^{25}$

O próximo capítulo abordará o questionamento ético sobre a privatização de prisões por empresas e as pesquisas feitas sobre o tema para comparar o desempenho das prisões geridas por empresas privadas e o pelo Estado.

\section{DIMENSÕES ÉTICAS}

De grande importância, as questões éticas permeiam os debates sobre privatização. Os críticos argumentam que o incentivo ao lucro do setor privado distorce os motivos e resulta em práticas corruptas e na baixa qualidade dos serviços, enquanto os defensores argumentam que as empresas privadas fornecem resultados comparáveis a um custo menor e o fazem sem causar mais danos do que às prisões públicas. ${ }^{26} 27$

Os Estados Unidos da América contam com aproximadamente 2,2 milhões de pessoas cumprindo pena em penitenciárias. Um em cada cem cidadãos e três ou mais em alguns estados estão em prisões. ${ }^{28} \mathrm{O}$ sistema estadunidense é recordista em condenação e o líder mundial em taxas de encarceramento; acrescentando-se as pessoas que estão em liberdade condicional, o número de pessoas supervisionadas pelo sistema de Justiça Criminal eleva-se a 7,3 milhões. Entre 1980 e 2012, o número total de prisioneiros estaduais e municipais nos Estados Unidos aumentou de 501.886 para 2.228.400 - um aumento de $344 \%$. ${ }^{29}$

Há literatura acadêmica e popular em grande quantidade nos Estados Unidos da América sobre o encarceramento, e a crítica majoritária é sobre o fenômeno que passou a ser conhecido por Complexo Industrial da Prisão. Destaca-se, adiante, duas de suas definições fornecidas por sites que divulgam a falta de ética com que é tratada o tema da prisão nos Estados Unidos da América:

\footnotetext{
${ }^{25}$ LINDSEY, 2016.

${ }^{26}$ LINDSEY, 2016.

${ }^{27}$ LUNDAHL, 2009.

${ }^{28}$ PEWTRUST. One in 31 U.S. Adults are Behind Bars, on Parole or Probation. Press Release, Pub. Safety Performance Project, mar. 2009

Disponível em: <https://www.pewtrusts.org/en/about/news-room/press-releases-and-statements/2009/03/02/onein-31-us-adults-are-behind-bars-on-parole-or-probation>. Acesso em: 2 jan. 2020.

${ }^{29}$ AVIRAM, Hadar. Are Private Prisons to Blame for Mass Incarceration and its Evils? Prison Conditions, Neoliberalism, and Public Choice. Fordham Urb. L.J. 411, 2014. Disponível em: <https://ir.lawnet.fordham.edu/ulj/vol42/iss2/2>. Acesso em: 3 jan. 2020.
} 
[...] termo que usamos para descrever os interesses sobrepostos do governo e da indústria que usam vigilância, policiamento e prisão como soluções para questões econômicas, problemas sociais e políticas ... [O poder sobre os presos] também é mantido ao auferir-se enormes lucros para empresas privadas que lidam com prisões e forças policiais; ajudando a obter ganhos por políticos "duros com o crime"; aumentando a influência do guarda prisional e de sindicatos de policiais; e eliminar a dissidência social e política de comunidades oprimidas que demandam autodeterminação e reorganização do poder nos EUA. ${ }^{30}$

O texto adiante elaborado por Eric Schlosser denota que "[ [... as prisões privadas são o mais óbvio, controverso seguimento de alto crescimento do Complexo Industrial Penitenciário e realmente essas definições extensas frequentemente mencionam o Complexo Industrial Penitenciário como o mais saliente exemplo de seu medo" $" 31$ :

\begin{abstract}
[...] o conjunto de interesses burocráticos, políticos e econômicos que
incentivam o aumento de gastos com prisão, independentemente da
\end{abstract}

necessidade real. O Complexo Industrial Penitenciário não é uma conspiração, guiando a política de justiça criminal do país a portas fechadas. É uma confluência de interesses especiais que deu à construção de prisões nos Estados Unidos um impulso aparentemente imparável. É composto por políticos, liberais e conservadores que usaram o medo do crime para obter votos; áreas rurais empobrecidas, onde as prisões tornaram-se uma pedra angular do desenvolvimento econômico; empresas privadas que consideram os cerca de US $\$ 35$ bilhões gastos anualmente em correções não como um fardo para os contribuintes estadunidenses, mas como um mercado lucrativo; e funcionários do governo cujos feudos expandiram-se junto com a população de presos. ${ }^{32}$

\footnotetext{
${ }^{30}$ CRITICAL RESISTANCE. What Is the PIC? What Is Abolition. Disponível em: <http://criticalresistance.org/about/not-so-common-language/>. Acesso em 4 jan.2020.

Texto original em ingles: [...] term we use to describe the overlapping interests of government and industry that use surveillance, policing, and imprisonment as solutions to economic, social and political problems.... [Power over inmates] is also maintained by earning huge profits for private companies that deal with prisons and police forces; helping earn political gains for "tough on crime" politicians; increasing the influence of prison guard and police unions; and eliminating social and political dissent by oppressed communities that make demands for selfdetermination and reorganization of power in the US.

31 SCHLOSSER, Eric. The Prison-Industrial Complex. Atlantic. Dec. 1998. Disponível em: < http://www.theatlantic.com/magazine/archive/1998/12/the-prison-industrialcomplex/

304669/. >. Acesso em: 4 jan. 2020.

${ }^{32}$ SCHOLSSER, Ibid..

Texto original em inglês: [A] set of bureaucratic, political, and economic interests that encourage increased spending on imprisonment, regardless of the actual need. The prison-industrial complex is not a conspiracy, guiding the nation's criminal-justice policy behind closed doors. It is a confluence of special interests that has given prison construction in the United States a seemingly unstoppable momentum. It is composed of politicians, both liberal and conservative, who have used the fear of crime to gain votes; impoverished rural areas where prisons have become a cornerstone of economic development; private companies that regard the roughly $\$ 35$ billion spent each year on corrections not as a burden on American taxpayers but as a lucrative market; and government officials whose fiefdoms have expanded along with the inmate population.
} 
Ainda com foco no tema da falta de ética do comportamento dos políticos, empresas e funcionários públicos, Hadar Aviram tece os seguintes comentários sobre a miséria humana:

\begin{abstract}
De fato, a literatura crítica das prisões geralmente atinge as empresas operadoras de prisões privadas, assumindo que o encarceramento privado é, por definição, pior do que o encarceramento público, ambas por razões ético-filosóficas e também porque sua estrutura com fins lucrativos cria um desincentivo ao investimento em melhorar as condições da prisão. Estas questões são razoáveis e compreensíveis. O conceito de empresas privadas projetadas para beneficiarem-se diretamente do confinamento e miséria humana é profundamente antiético e problemático. ${ }^{33}$
\end{abstract}

A contratação de empresas privadas para consecução de punição criminal com certeza acarreta questões éticas que são ignoradas em razão da natureza contratual lucrativa da indústria prisional, que considera os presos como mercadorias. Avihai Dorfman e Alon Harel elaboraram dois argumentos convincentes sobre a ética da prisão privatizada: em seu primeiro argumento, as empresas privadas não podem executar adequadamente os serviços públicos porque os bens são inerentemente públicos e, por esse motivo, são reconhecidos apenas quando realizados por funcionários do Estado, pois os indivíduos são encarcerados por cometer crimes contra o Estado que, por sua vez, é o único responsável pela sua habilitação e supervisão. O Estado não pode legalmente renunciar à sua obrigação de processar infratores; o segundo argumento é mais direto, ao defender que apenas os funcionários públicos podem promover as execuções do Estado; por conseguinte, este serviço não pode ser prestado por empregado contratado por prisões particulares. ${ }^{34}$

Por serem entidades com fins lucrativos, as prisões privadas procuram presos para lotar seus quadros, participando de licitações para aceitar presos de outras prisões superlotadas. ${ }^{35}$ Os

\footnotetext{
${ }^{33}$ AVIRAM, 2016.

Texto original em inglês: Indeed, critical prison literature commonly takes on private prison companies, assuming that private incarceration is, by definition, worse than public incarceration, both for philosophical-ethical reasons and because its for-profit structure creates a disincentive to invest in improving prison conditions. These concerns are reasonable and understandable. The concept of private enterprises designed to directly benefit from human confinement and misery is profoundly unethical and problematic.

${ }^{34}$ DORFMAN, Avihay; HAREL, Alon. The Case Against Privatization. Wiley Periodicals, Inc.. Philosophy \& Public Affairs, no. 1, 2013.

${ }^{35}$ SILVA, Nicole Mitchell Ribeiro. O Trabalho nas Prisões dos EUA: "Não É um Sistema de Justiça, É um Negócio" Disponível <http://www.mprj.mp.br/documents/20184/1183784/Nicole_Mitchell_Ribeiro_da_Silva.pdf >. Acesso em: 2 jan. 2020 .
} 
autores entendem que as prisões privadas operam sem disposições adequadas e sem a devida responsabilidade; e tecem como exemplo as prisões privadas, que geralmente não classificam corretamente os presos quanto à periculosidade ou por ignorar a sua classificação. Essa inobservância de classificação resulta na mistura de presos de todos os níveis de risco. A questão é a atitude das prisões privadas, que frequentemente elevam seus interesses lucrativos acima da promoção da qualidade de suas instalações. ${ }^{36}$

Para o contínuo funcionamento de seus negócios, as prisões privadas necessitam de fornecimento contínuo de prisioneiros. Os autores afirmam, ainda, que as empresas gestoras de prisões privadas forçam limites éticos na seara política, com a prática de lobby para sentenças mais duras e mais longas para garantir sua permanência no negócio; bem como um conselho de liberdade condicional mais rigoroso. A Força-Tarefa de Justiça Criminal é um comitê amplamente conhecido que pressiona por mais medidas punitivas e sentenças severas, havendo, entre os seus membros, representantes das empresas gestoras de prisões privadas. Percebe-se claramente uma questão ética nesta representatividade. ${ }^{37}$

\subsection{REINCIDÊNCIA DE DESEMPENHO}

A taxa de reincidência é a principal medida para aferir o desempenho da prisão. Várias pesquisas foram realizadas, majoritariamente no estado da Flórida, para avaliar o desempenho da prisão privada, comparando taxas de reincidência de internos em prisões operadas pelo setor público e setor privado. Em 2005, William D. Bales et al. realizaram um estudo no estado da Flórida com base neste padrão, pelo período de 36 meses, utilizando-se como objeto de análise a diferença de reincidência em homens adultos e jovens infratores. A reincidência foi medida em dois níveis: reincidência e condenação. Ambos os níveis requeriam que a condenação fosse considerada reincidência. Para cada grupo, a pesquisa não encontrou estatisticamente diferença significativa de reincidência entre presos em prisões públicas e privadas. A conclusão alcançada sugere que as prisões privadas não têm efeito sobre a reincidência em comparação com instituições estatais. Este estudo conflita diretamente com o argumento de que prisões privadas oferecem melhor qualidade de serviços em relação às prisões públicas. ${ }^{38}$

\footnotetext{
${ }^{36}$ AVIHAI, 2013.

${ }^{37}$ AVIHAI, Ibid.

${ }^{38}$ AVIHAI, Ibid.
} 
Em 2008, Andrew L. Spivak e Susan F. Sharp conduziram um estudo no estado de Oklahoma, com uma amostra de 23.000 indivíduos, aprimorando a metodologia de estudos anteriores e o consequente aumento da confiabilidade de seus resultados. Foram comparadas taxas de reincidência de infratores libertados de instituições públicas e privadas, considerandose o tempo de permanência em qualquer centro correcional. A pesquisa revelou que os detentos do sexo masculino que passaram mais tempo em instalações privadas tiveram taxas de reincidência significativamente maiores em relação aos que passaram mais tempo em estabelecimentos públicos. Ao considerar todos os presos, os resultados revelaram que as taxas de reincidência dos presos libertados de prisões públicas de segurança média eram significativamente mais baixas em relação aos libertados de prisões privadas. Concluiu-se dessa pesquisa que o encarceramento em prisões privadas não aumenta a probabilidade de reincidência de um infrator, no entanto, é importante reconhecer que esses achados não indicam necessariamente que as prisões privadas aumentam a probabilidade de reincidência. ${ }^{39}$

Em 2013, Grant Duwe e Valerie Clark também realizaram uma pesquisa comparando a reincidência pública e a privada em prisões com uma amostra de aproximadamente 10.000 presos do estado de Minnesota. O objeto da pesquisa foi o estabelecimento de uma relação causal entre a prisão privada e a probabilidade de reencarceramento e recondenação. $\mathrm{O}$ resultado da pesquisa levou à conclusão de que na prisão privada aumentou-se significativamente a probabilidade de reencarceramento (13\%) e recondenação (22\%). A prisão privada não aumentou a probabilidade de reencarceramento por nova ofensa ou violação técnica. Os autores comentam que cinco medidas adotadas pela prisão privada diminuíram significativamente o aumento de risco de reincidência. Conclui-se, também, que a reincidência é uma medida difícil de avaliar-se, pois utilizam-se parâmetros diferentes nas pesquisas, além da forte influência de fatores sociais e estruturais existentes fora da prisão. Logo, não há uma indicação firme de que as prisões privadas produzam diferentes taxas de reincidência em relação às prisões públicas.

\subsection{CUSTOS FINANCEIROS}

\footnotetext{
${ }^{39}$ SPIVAK, Andrew L.; SHARP, Susan F. Sharp . Crime \& Delinquency. v. 54 n. 3, p. 482-508. Sage Publications, 2008. 2 Disponível <https://shareok.org/bitstream/handle/11244/25482/10.1177.0011128707307962.pdf?sequence=1 >. Acesso em: 2 jan. 2020.
} 
A análise do custo benefício é uma forma adicional de verificar o desempenho de prisões privadas. Um dos princípios fundamentais da privatização das prisões era seu potencial em reduzir custos. Andrew Spivak e Susan F. Sharp relatam que uma das empresas prisionais privadas operantes nos Estados Unidos da América informou recentemente que a existência das prisões privadas auxilia a controlar o custo das prisões públicas. ${ }^{40}$ Supõe-se, frequentemente, que as prisões privadas podem ser construídas de forma mais barata e mais rapidamente por estarem livres de aprovação dos eleitores do orçamento do Estado, no entanto, os contribuintes ainda pagam pelas prisões particulares de maneiras menos perceptíveis. Empresas privadas podem assumir os custos operacionais da prisão, mas o Estado ainda deve pagar para monitorar a instalação; as prisões particulares também recebem benefícios de depreciação, incentivos fiscais e subsídios que saem do bolso dos contribuintes. Ao considerar todas as despesas, as prisões privadas podem custar um pouco mais do que as prisões administradas pelo Estado. ${ }^{41}$ Em síntese, os economistas estimam que os custos de longo prazo das prisões privadas podem atender ou exceder as economias de curto prazo, observando-se que as prisões privadas frequentemente manipulam os custos trabalhistas para operar em um orçamento menor. ${ }^{42}$

Em 2001, os custos de mão de obra, como salários, representaram $65 \%$ do orçamento público das prisões. Ao mesmo tempo, os funcionários de prisões privadas receberam um salário máximo $41 \%$ menor do que os funcionários das prisões públicas. Verificou-se, dessa forma, que as prisões públicas tinham uma média de rotatividade de $16 \%$ ao ano, enquanto as prisões privadas registraram uma taxa de rotatividade mais de três vezes superior a $52 \%$. Mesmo com uma maior taxa de rotatividade, as prisões privadas ofereceram 39\% menos horas de treinamento para seus agentes penitenciários do que as prisões públicas.

\subsection{DIREITOS DOS DETENTOS}

Os direitos concedidos aos detentos em instituições privadas também podem medir o seu desempenho. A Quinta e a Décima Quarta Emendas Constitucionais dos Estados Unidos da América garantem os direitos do devido processo legal do acusado; e a Oitava Emenda

\footnotetext{
${ }^{40}$ SPIVAK, 2008.

${ }^{41}$ WACQUANT, Loïc. The Wedding of Workfare and Prisonfare Revisited. Entrevista de Volker Eick e Karen J. Winkle. Article in Social justice, SanFrancisco, Calif., 2011. Disponível em: <file:///C:/Users/alber/Documents/AB\%23Revisao\%20Textos/Artigos/Elaboracao/ART_ELAB\%2300017_Marc elo\%20Sampaio\%20Etica\%2028dez19/PDF010\%23Wacquant_The_Wedding_of_Workfare_and_Prisonfare_Re visited.pdf>. Acesso em: 4 jan. 2020.

${ }^{42}$ SPIVAK, Ibid.
} 
Constitucional protege os presos de punições cruéis e incomuns. ${ }^{43}$ Os presos enfrentam muitas barreiras para acesso aos tribunais. As barreiras organizacionais para registrar queixas são definidas como ameaças feitas pelo pessoal da prisão para transferir presos. As barreiras estruturais para a apresentação de queixas foram definidas como falta de acesso a bibliotecas e assistência jurídica. $\mathrm{O}$ estudo incluiu aproximadamente 80 entrevistas de detentos públicos e privados. Os resultados concluíram que os presos públicos e privados experimentam barreiras organizacionais, no entanto, na prisão privada os presos experimentam muito mais barreiras estruturais. $\mathrm{O}$ acesso aos tribunais é um dos direitos mais valiosos dos detentos. Portanto, é um sinal de fraco desempenho para as prisões privadas diminuir os direitos dos presos como forma de garantir lucros. ${ }^{44}$

\subsection{QUALIDADE DO CONFINAMENTO}

A qualidade de confinamento também é uma medida de desempenho das prisões privadas e termômetro do agir ético. Avalia-se a qualidade do confinamento para verificar-se se as prisões privadas realmente fornecem serviços de qualidade superior em comparação às prisões públicas. As medidas de qualidade de confinamento são: a segurança, a proteção, a ordem, o cuidado, a atividade e a Justiça.

Vários estudos avaliaram a segurança e a ordem das prisões privadas e públicas. Uma pesquisa elaborada por Andrew L. Spivak e Susan F. Sharp constatou que os níveis de segurança interna e a atividade de quadrilhas são relativamente semelhantes entre as prisões públicas e privadas. No entanto, há taxas mais altas de uso de drogas em prisões privadas que indicaram um nível mais fraco de segurança externa. O estudo também encontrou níveis mais altos de conduta imprópria dos presos em prisões privadas. Um exame mais detalhado dos incidentes violentos nas prisões sugeriu que as prisões privadas têm o maior número de denúncias de assalto entre presos nas prisões estaduais e federais. ${ }^{45}$

Uma pesquisa com presos publicada em 2008 afirmou que os presos em instalações privadas relataram piores condições de saneamento e serviços de alimentação do que os presos

43 ESTADOS UNIDOS DA AMÉRICA. Constituição e Emendas. Disponível em: $<$ https://www.senate.gov/civics/constitution_item/constitution.htm >. Acesso em: 7 jan. 2020.

${ }^{44}$ MILLER, A. J. Prisoners' access to the court: a qualitative study of the barriers inmates must overcome to access the courts. The Justice Professional, 10, 361-377, 1998.

${ }^{45}$ SPIVAK, 2008. 
em estabelecimentos públicos. Em geral, as prisões privadas tendem a receber pontuação mais baixa no quesito de atendimento e condições quando comparadas às prisões públicas. ${ }^{46}$

A atividade como uma medida da qualidade do confinamento refere-se ao acesso do interno à educação, à reabilitação, ao tratamento e a outros programas. As transferências entre prisões públicas e privadas geralmente interrompem o plano de tratamento ou a faixa educacional de um preso. Uma vez transferidos para uma instituição privada, certos programas podem não estar mais disponíveis para os presos. Isso representa uma séria interrupção no curso de reabilitação de um preso. Uma comparação entre prisões públicas e privadas em 2006 constatou que as prisões privadas têm proporções mais altas de prisioneiros matriculados em programas. $^{47}$

As questões éticas abordadas neste capítulo, apesar de não serem exaustivas, denunciam a sobreposição dos valores financeiros dos gestores das prisões privadas sobre os valores de bem-estar material e psicológicos dos internos. No próximo capítulo comentar-se-á sobre o que ocorre na atualidade nos Estados Unidos da América sobre a não aceitação pela população das prisões privadas e a tendência política para sua (des)continuidade no âmbito federal e estadual.

\section{OS ESTADOS UNIDOS DA AMÉRICA ESTÃO ABANDONANDO A UTILIZAÇÃO DAS PRISÕES GERIDAS POR EMPRESAS PRIVADAS?}

A mídia está muito ativa sobre este tema. Recentemente, os estados da Federação estão editando leis para abolir prisões privadas e o mercado está cortando os laços com as instalações privadas. As críticas às prisões privadas lucrativas estão refletindo-se na política e gastos. Os legisladores dos estados da Califórnia e Nevada baniram a operação com prisões privadas. A quantidade de presos diminuiu $12 \%$ nos últimos cinco anos e mais prisões estão fechando. $\mathrm{Na}$ medida em que as prisões privadas necessitam de ocupação para operar e gerar lucros, há uma preocupação dos executivos das empresas gestoras de prisões privadas, pois a queda dos números poderá significar o término dessa operação. ${ }^{48}$

\footnotetext{
46 SPIVAK, Ibid.

${ }^{47}$ SPIVAK, Ibid.

${ }^{48} \mathrm{KIM}$, Catherine. Private prisons face an uncertain future as states turn their backs on the industry. dez. 2019 ,

Disponível em: <https://www.vox.com/policy-and-politics/2019/12/1/20989336/private-prisons-states-banscalifonia-nevada-colorado>. Acesso em: 5 jan. 2020.
} 
Em 2016 o governo Obama ordenou a diminuição do uso das prisões privadas após a informação de altos índices de contrabando, violência e uso de força nas prisões privadas. No entanto, o governo Trump, em 2017, reativou o uso de prisões privadas no âmbito federal com edição da política de separação das famílias dos imigrantes. Em respostas às atitudes de Trump, os estados e o mercado começaram a tomar suas próprias ações contra essa indústria. $\mathrm{O}$ ano de 2019 foi muito difícil para prisões privadas, devido à política de tolerância zero na fronteira entre México e Estados Unidos da América; o povo americano repudiou a separação das famílias e as condições em que os imigrantes foram detidos; além dos mais, os ativistas denunciaram que as empresas gestoras de prisões privadas e alguns bancos de Wall Street estavam obtendo lucros com a detenção dos imigrantes.

A maioria dos estados da Federação está planejando tomar medidas similares em favor do abandono das prisões privadas. No mês de novembro de 2020 o estado do Colorado propôs uma lei para fechamento da maioria das prisões privadas. A partir de março de 2020 o Banco J. P. Morgan e mais sete instituições bancárias anunciaram que não mais concederão linhas de créditos às prisões privadas e ao seu nicho de mercado. ${ }^{49}$

\footnotetext{
${ }^{49}$ HADAVI, Tala. Why Banks could be killing private prisons. Diamond Green. jan.2020, Disponível em: <https://www.cnbc.com/2020/01/02/why-private-prisons-geo-group-and-corecivic-arestruggling-under-trump.html>. Acesso em: 4 jan. 2020.
} 


\section{CONSIDERAÇÕES FINAIS}

O presente estudo ateve-se em pesquisar algumas questões éticas que permeiam a utilização da gestão de prisões por empresas privadas, como uma resposta à ineficiência estatal. A privatização de uma forma ou outra está disseminada na industrial correcional estadunidense, mas a maior controvérsia relaciona-se às prisões operadas por proprietários privados. Há muitos pontos de discussão entre oponentes e apoiadores da administração privada das prisões, vários deles listados neste estudo e investigados empiricamente; e não há uma resolução, exceto, como exposto, uma forte tendência ao abandono da gestão de prisões de forma privada por todos os motivos éticos já expostos. No entanto, os pesquisadores continuarão seu trabalho em clarificar o debate e, principalmente, debater as questões éticas envolvidas nesta indústria. Do ponto de vista filosófico, entretanto, a base onde está alicerçada a administração privada de prisões é insustentável, quando inserida no contexto de uma tradição constitucional liberal-democrata como são os Estados Unidos da América, eis que os argumentos expostos apresentam um significativo dilema ético que se refere aos direitos fundamentais e dignidade da pessoa humana. 


\section{REFERÊNCIAS}

ANDERSON, George. Prisons for Profit: Some ethical and practical problems. Nov., 2018. Disponível em: <https://www.americamagazine.org/issue/389/article/prisons-profit>. Acesso em: 31 dez. 2019.

ARMSTRONG, Gaylene Styve. Private vs. Public Operation of Juvenile Correctional Facilities. New York: LFB Scholarly Publishing LLC, 2001.

AVIRAM, Hadar. Are Private Prisons to Blame for Mass Incarceration and its Evils? Prison Conditions, Neoliberalism, and Public Choice. Fordham Urb. L.J. 411, 2014. Disponível em: <Available at: https://ir.lawnet.fordham.edu/ulj/vol42/iss2/2>. Acesso em: 3 jan. 2020.

BLAKELY, Curtis R. Blakely; BUMPHUS, Vic W. Bumphus. Private and Public Sector Prisons: A Comparison of Select Characteristics, jun. 2004. Disponível em: $<$ https://www.uscourts.gov/federal-probation-journal/2004/06/private-and-public-sectorprisons-comparison-select>. Acesso em: 2 jan. 2020.

CALVERT-HANSON, L. S. The privatization of corrections movement: A decade of change. Journal of Contemporary Criminal Justice, 1991, 7, 1-20. Disponível em: <https://journals.sagepub.com/doi/pdf/10.1177/104398629100700103>. Acesso em: 3 jan. 2020 .

CHANG, Tracy F.H.;THOMPKINS, Douglas E. Corporations Go to Prisons: The Expansion of Corporate Power in the Correctional Industry Disponível em: <https://citeseerx.ist.psu.edu/viewdoc/download;jsessionid=6636C45A3014B5ED8EC0625E 2B8F4126?doi=10.1.1.462.6544\&rep=rep1\&type=pdf >. Acesso em: 2 jan. 2020.

CRITICAL RESISTANCE. What Is the PIC? What Is Abolition. Disponível em: $<$ http://criticalresistance.org/about/not-so-common-language/>. Acesso em 4 jan.2020.

DORFMAN, Avihay; HAREL, Alon. The Case Against Privatization. Wiley Periodicals, Inc.. Philosophy \& Public Affairs, no. 1, 2013.

ESTADOS UNIDOS DA AMÉRICA. Constituição e Emendas. Disponível em: <https://www.senate.gov/civics/constitution_item/constitution.htm >. Acesso em: 7 jan. 2020.

FERNANDES, Dinorá Carla de Oliveira Rocha; COSTA, Raiane Ingrid Pereira. Auxílio reclusão: uma releitura com base nos princípios constitucionais. Revista Juridica, [S.1.], v. 1 , n. 34, p. 112-137, fev. 2014. ISSN 2316-753X. Disponível em: <http://revista.unicuritiba.edu.br/index.php/RevJur/article/view/788/601>. Acesso em: 19 abr. 2020. doi:http://dx.doi.org/10.21902/revistajur.2316-753X.v1i34.788.

HACKETT, Judith et. Al. Issues in Contracting for the Private Operations of Prison and Jails. Oct. 1987. Disponível em: <https://books.google.com.br>. Acesso em: 31 dez. 2019.

HADAVI, Tala. Why Banks could be killing private prisons. Diamond Green. jan.2020. Disponível em: <https://www.cnbc.com/2020/01/02/why-private-prisons-geo-group-andcorecivic-are-struggling-under-trump.html>. Acesso em: 4 jan. 2020. 
HARDING, Richard, Private Prisons, in Crime and Justice: Review of Research. Michael H. Tonry ed: 2001, p. 265, 268-269.

KIM, Catherine. Private prisons face an uncertain future as states turn their backs on the industry. dez. 2019. Disponível em: <https://www.vox.com/policy-andpolitics/2019/12/1/20989336/private-prisons-states-bans-califonia-nevada-colorado>. Acesso em: 5 jan. 2020.

LINDSEY, Andrea M. The Privatization Debate: A Conceptual Framework for Improving (Public and Private) Corrections. 2016. Disponível em: <https://www.researchgate.net/publication/305418634_The_Privatization_Debate_A_Concep tual_Framework_for_Improving_Public_and_Private_Corrections/link/5a1d8d540f7e9b2a531 768ce/download>. Acesso em: 2 jan. 2020

LONG, Charles H. Privare prisons: cons and pros. New York: Oxford University Press: 1990.

LUNDHAL, Brad. W. Prison Privatization A Meta-analysis of Cost and Quality of Confinement Indicators. Research on Social Work Practice. v.19 nr. Sage Publications: 2009. Disponível em: 〈https://www.epsu.org/sites/default/files/article/files/luhndahl-prisons-.pdf>. Acesso em: 2 jan. 2020.

MILLER, A. J. Prisoners' access to the court: a qualitative study of the barriers inmates must overcome to access the courts. The Justice Professional, 10, 361-377, 1998.

OSTERMANN, Fábio Maia. A PRIVATIZAÇÃo DE PRESÍDIOS COMO ALTERNATIVA AO CAOS PRISIONAL. Disponível em: < https://www.ufrgs.br/ressevera/wp-content/uploads/2010/08/v02-n01-artigo02privatizacao.pdf $>$. Acesso em: 3 jan.2020.

PEWTRUST. One in 31 U.S. Adults are Behind Bars, on Parole or Probation. Press Release, Pub. Safety Performance Project, mar. 2009. Disponível em: $<$ https://www.pewtrusts.org/en/about/news-room/press-releases-andstatements/2009/03/02/one-in-31-us-adults-are-behind-bars-on-parole-or-probation>. Acesso em: 2 jan. 2020.

POSEN, David E. Managing a Correctional Marketplace: Prison Privatization in the United States of America and United Kingdom.2003. Disponível em:<http://www.antoniocasella.eu/nume/Pozen_prison_privatization_2003.pdf >. Acesso em: 31 dez. 2019.

SCHLOSSER, Eric. The Prison-Industrial Complex. Atlantic. Dec. 1998. Disponível em: < http://www.theatlantic.com/magazine/archive/1998/12/the-prison-industrialcomplex/304669/. >. Acesso em: 4 jan. 2020.

SILVA, Nicole Mitchell Ribeiro. O Trabalho nas Prisões dos EUA: "Não É um Sistema de Justiça, É um Negócio” Disponível <http://www.mprj.mp.br/documents/20184/1183784/Nicole_Mitchell_Ribeiro_da_Silva.pdf>.

SPIVAK, Andrew L.; SHARP, Susan F. Sharp . Crime \& Delinquency. v. 54 n. 3, p. 482508. Sage Publications, 2008. Disponível em: 
$<$ https://shareok.org/bitstream/handle/11244/25482/10.1177.0011128707307962.pdf?sequenc $\mathrm{e}=1>$. Acesso em: 2 jan. 2020.

STARR, Paul. (1988). The meaning of privatization. Yale Law and Policy Review, 6, 641.1981. Disponível em: <https://www.princeton.edu/ starr/articles/articles80-89/StarrMeaningPrivatization-88.htm>. Acesso em: 2 jan. 2020.

STILLMAN, Sarah. Get Out of Jail, Inc. Does the alternatives-to-incarceration industry profit from injustice? June 23, 2014 Issue. Disponível em: <https://www.newyorker.com/magazine/2014/06/23/get-out-of-jail-inc>. Acesso em: 1 jan. 2020

WACQUANT, Loïc. The Wedding of Workfare and Prisonfare Revisited. Entrevista de Volker Eick e Karen J. Winkle. Article in Social justice, SanFrancisco, Calif., 2011. Disponível em: <https://www4.shu.ac.uk/research/cresr/sites/shu.ac.uk/files/weddingworkfare-prisonfare-revisited.pdf $>$. Acesso em: 4 jan. 2020. 